\title{
Vibration electrospinning of Polyamide-66/Multiwall Carbon Nanotube Nanocomposite: introducing electrically conductive, ultraviolet blocking and antibacterial properties
}

\author{
Salar Zohoori ${ }^{1}$, Masoud Latifi ${ }^{*}$, Abolfazl Davodiroknabadi ${ }^{3}$, Mohammad Mirjalili ${ }^{1}$ \\ ${ }^{1}$ Islamic Azad University, Department of Textile Engineering, Yazd Branch, Yazd, Iran \\ ${ }^{2}$ Amirkabir University of Technology, Textile Engineering Department, Textile Research and Excellence Centers, Tehran, Iran \\ ${ }^{3}$ Islamic Azad University, Department of Design and Clothing, Yazd Branch, Yazd, Iran \\ "Corresponding author: e-mail: latifi@iauyazd.ac.ir
}

\begin{abstract}
Fabrication of electro-conductive fiber is a novel process. Nanocomposites of multiwall carbon nanotube/polyamide66 were produced by electrospinning with different amounts of multiwall carbon nanotube. Field emission scanning electron microscope and Fourier transform infrared spectroscopy of samples proved the existence of multiwall carbon nanotube distribution in polyamide 66 nanofibers. Results showed that electro conductivity of electrospun multiwall carbon nanotube/polyamide 66 nano fiber has increased in comparison with electrospun polyamide 66. Moreover, UV blocking of samples was investigated which has shown that using multiwall carbon nanotube in polyamide 66 increases UV blocking of fibers. Furthermore, anti-bacterial activity of nanocomposite showed that these nanocomposites have antibacterial property against both Staphylococcus Aureus and Escherichia Coli bacteria according to AATCC test method.
\end{abstract}

Keywords: MWCNT, PA66, Electrospinning, Electrical Conductivity, UV-Blocking, Antibacterial.

\section{INTRODUCTION}

During the past decades, nanotechnology has exposed a novel section among the materials. The application of nanotechnology has quickly grown in several areas, particularly in textile industry ${ }^{\mathbf{1}-3}$. Producing ultrafine fiber such as nanofiber is carried out through electrospinning which is the most usual and best-known technique that can overcome the surface tension of polymer in order to create sub-micrometer fibers ${ }^{4}$. The main characteristics of electrospinning include high aspect ratio, specific surface area, dimensional stability, high porosity and small diameter ${ }^{5-7}$. This method is a conventional approach for fabricated nanocomposite ${ }^{8}$.

Electrospinning process contains a polymer solution which is charged and by overcoming the surface tension, a thin layer of web polymer is formed on a surface ejection of polymer solution, causing the elongation of polymer and firmed ultra-thin fiber ${ }^{9-11}$.

Electrospinning nanofibers have many medical applications such as wound dressing ${ }^{12}$, drug delivery, dental restoration, as well as engineering applications such as filtration, and tissue. Poor mechanical properties of these fibers (like Young's modulus) can be enhanced by combining nano-materials such as carbonaceous nanomaterials with these fibers ${ }^{13}$.

Multi-walled carbon nanotubes (MWCNTs) have attracted considerable attention because of their unique characteristics such as electrical, optical and mechanical properties ${ }^{8,14,15}$, high surface to volume ratio, high conductivity, low mass density and small size ${ }^{16-18}$.

The most processable fiber which has special properties such as high strength, toughness and elasticity, is polyamide-66 (PA66). It is a semi-crystalline polymer having oil and heat resistance. Formic acid and Metacrosol are two common solvents that can solve it at room temperature in order for electrospinning. Obviously, its poor humidity adsorption and non-electrical conductivity are among the disadvantages of this fiber. In order to overcome these problems, blending of PA66 with MWCNT is suggested because by blending, its properties will be balanced ${ }^{19}$. Chang Jae Lee et al. reported the dispersion of CNT in the PA66 phase because of high affinity, and reported the higher electrical conductivity of PA66/carbon nanotube ${ }^{10}$. Clemente et al. reported the better dielectric, crystallinity and rheology properties of PA66/MWCNT ${ }^{24}$.

In this paper, nanocomposites of MWCNT/PA66 with different concentration of carbon nanotubes were electrospun and its properties such as UV-blocking, antibacterial and electrical conductivity was investigated.

\section{EXPERIMENTAL}

\section{Material and Methods}

For the purpose of this study, we prepared PA66 granule from Aldrich (N66 74712) Company; Formic acid 99\% from Merck, MWCNT with outside diameter of $20-30 \mathrm{~nm}$ and inside diameter of 5-10 nm and specific surface area of more than $110 \mathrm{~m}^{2} / \mathrm{g}$ from US Nano Company were prepared. A suspension containing different loadings of MWCNT in the solution of PA66/ formic acid was prepared and was sonicated for $30 \mathrm{~min}$ at $50^{\circ} \mathrm{C}$. A Euronda ultrasonic bath model Eurosonic 4D, $350 \mathrm{~W}, 50 / 60 \mathrm{~Hz}$ (Italy) was used. For electrospinning, the distance between nozzle and collector was $15 \mathrm{~cm}$, pumping rate was $0.1 \mathrm{ml} / \mathrm{h}$ and spinning potential was $25 \mathrm{kV}$. More information on electrospinning parameters is given in Table 1. An ultrasonic generator was added to the device in order to obtain homogenate suspension during electrospinning (Fig. 1). This device provides vibration at $20 \mathrm{kHz}$. Without this device, nanomaterial might be aggregate, so ultrasonic device (vibrating electrospinning) can help to improve distribution of multi wall carbon nanotube during electrospinning. The Nanocomposites were collected on the Aluminum foil. The FTIR (Fourier Transform Infrared) spectra were obtained by BRUKER TENSOR27. The morphology 
Table 1. Parameters of electrospinning

\begin{tabular}{|c|c|c|c|c|c|c|}
\hline Parameter & $\begin{array}{c}\text { Pumping rate } \\
{[\mathrm{ml} / \mathrm{h}]}\end{array}$ & $\begin{array}{c}\text { Voltage } \\
{[\mathrm{kV}]}\end{array}$ & $\begin{array}{c}\text { Distance of nozzle to collector } \\
{[\mathrm{cm}]}\end{array}$ & $\begin{array}{c}\text { Collector speed } \\
{[\mathrm{rpm}]}\end{array}$ & $\begin{array}{c}\text { Traverse speed } \\
{[\mathrm{m} / \mathrm{min}]}\end{array}$ & $\begin{array}{c}\text { Temperature } \\
{[\mathrm{C}]}\end{array}$ \\
\hline Value & 0.1 & 25 & 15 & 150 & 0.3 & 28 \\
\hline
\end{tabular}

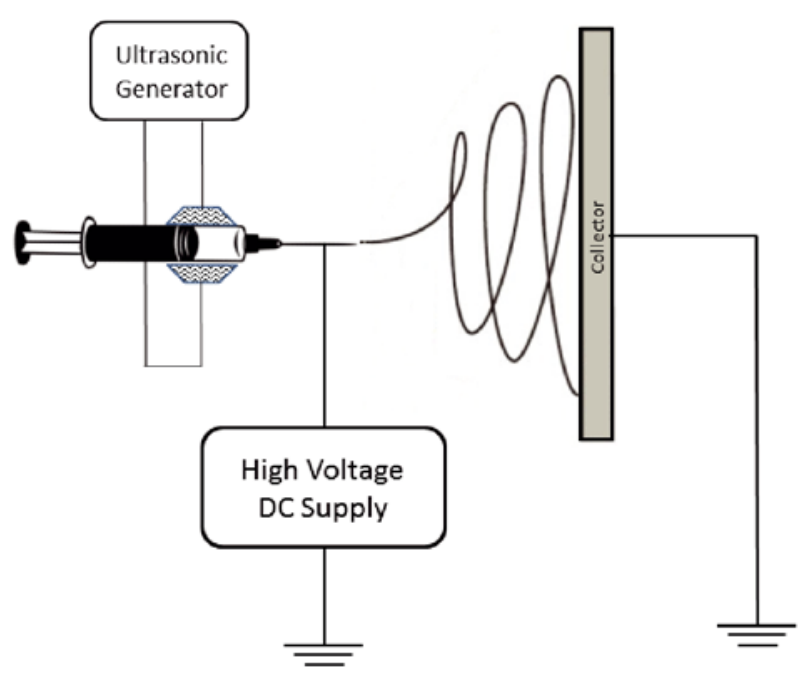

Figure 1. Schematic diagram of the vibration electrospinning

of nanofibers was observed by field emission scanning electron microscope (FE-SEM) MIRA3-TESCAN. UV-blocking properties of samples were determined using Perkin Elmer Lambda UV-vis spectrophotometer. Electrical surface resistivity was investigated by Hioki digital multimeter model 3256-50, Japan.

\section{RESULTS AND DISCUSSION}

\section{Microscopic analysis}

Figure 2 shows the morphologies of electrospun nanofibers and MWCNT's. According to FE-SEM images, the electrospun nanofibers were formed without any beads. Also it is possible to authenticate the MWCNTs on the surface of electrospun samples at higher magnification. The diameters of MWCNTs and nanofibers range between 20 to $32 \mathrm{~nm}$ and 24 to $55 \mathrm{~nm}$, respectively. The average diameter of nanofibers was calculated according to Eq. (1)

$$
D n=\frac{\sum n i D i}{\sum n i}
$$

Where $D n$ is the diameter of fibers, and $n i$ and $D i$ are number and diameter of each fiber, respectively.

\section{FTIR analysis}

Functional groups of the samples were studied by FT-IR spectroscopy. As shown in Figure 3 the peak at $1640 \mathrm{~m}^{-1}$ shows the existence of $\mathrm{C}=\mathrm{C}$ bond. For PA66, the characteristic peaks appear at $3509 \mathrm{~cm}^{-1}(\mathrm{~N}-\mathrm{H})$, $3313 \mathrm{~cm}^{-1}\left(\mathrm{CH}_{2}\right)$ and $1749 \mathrm{~cm}^{-1}(\mathrm{C}=\mathrm{O})$. Therefore, the results proved the existence of PA66 and carbon compound.

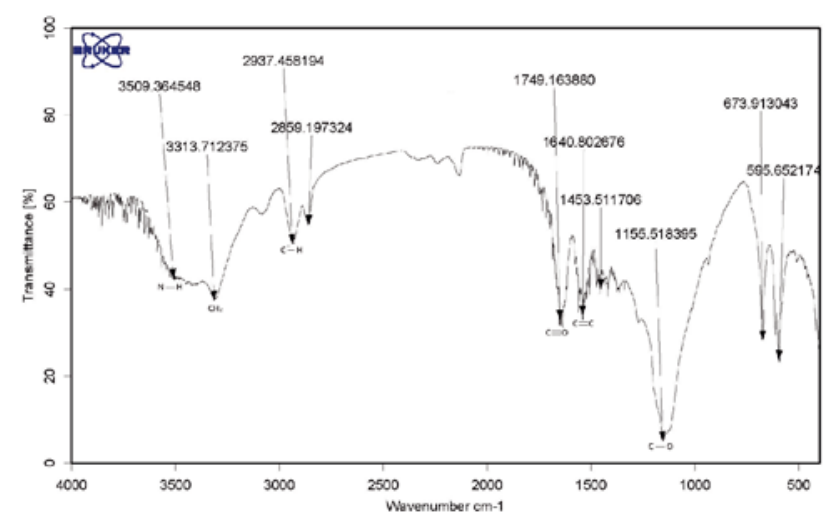

Figure 3. FT-IR spectrum of PA66/MWCNT electrospun nanocomposi

\section{Electrical Conductivity}

One of the most important physical properties of CNT/PA66 nano-composite is electrical conductivity. The electrical conductivity of raw sample (PA66 electrospun with $0.00 \% \mathrm{MWCNT}$ ) and treated samples were compared. Figure 4 shows the conductivity of various MWCNT loadings for electrospun fibers. As it can be seen, by increasing MWCNT from $0 \%$ to $1 \%$, the electrical conductivity increases significantly. However, increasing MWCNT from $1 \%$ to $4 \%$ enhances the electrical conductivity but not as much as $0 \%$ to $1 \%$. It can

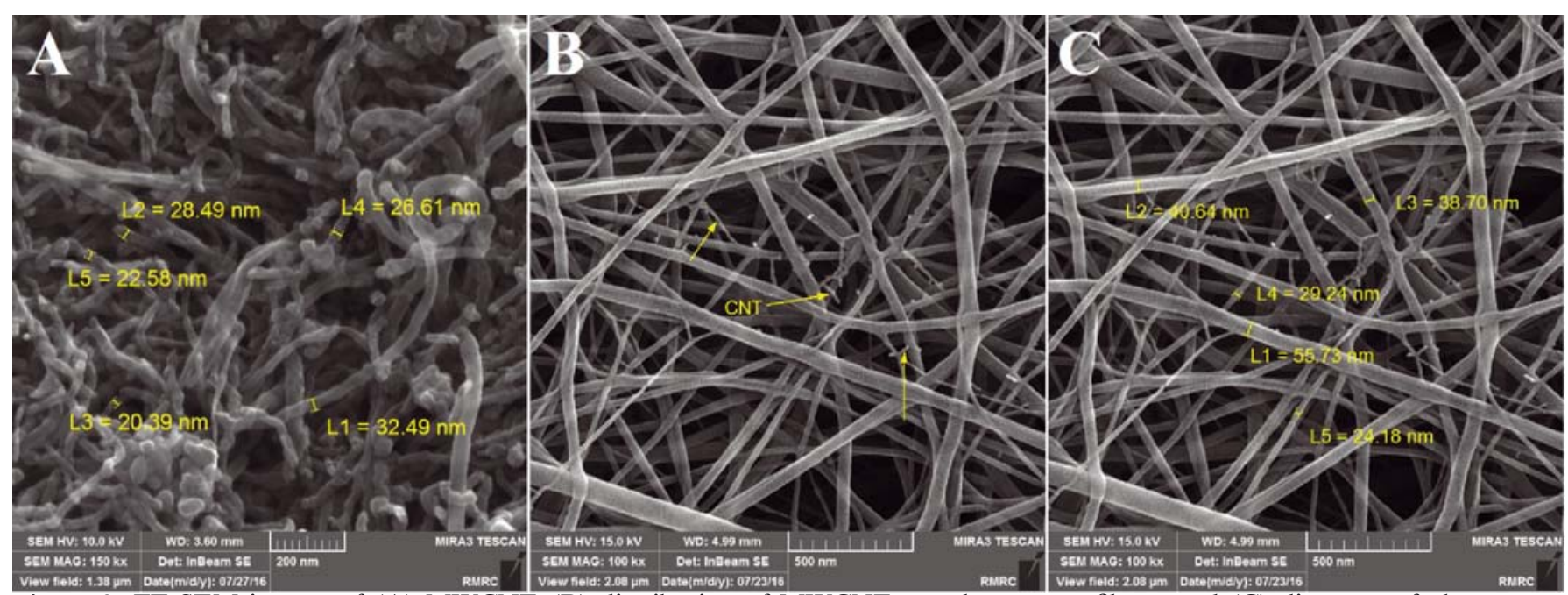

Figure 2. FE-SEM images of (A) MWCNT, (B) distribution of MWCNTs on electrospun fibers, and (C) diameter of electrospun nanofibers 
be explained by percolation theory. By observing Table 2 , one can easily understand that the conductivity of raw sample was zero while the electrical resistance of treated samples was about $10^{10} \Omega$ /square, $10^{6} \Omega$ /square for samples $\mathrm{A}, \mathrm{B}$ and $10^{3} \Omega$ /square for samples $\mathrm{C}$ and $\mathrm{D}$, respectively. In other words, by increasing the percentage of MWCNTs, the electrical conductivity is increased. It means that enhancing the MWCNT concentration had a perceptible effect on the electrical conductivity of PA66 nanofibers. This can be explained by better contact between MWCNTs. The polymer barrier between adjacent MWCNTs may reduce the conductivity of the samples. Chien et al. reported the electrical conductivity of polyacrylonitrile/carbon nanotube ranging from $10^{2}$ to $10^{5}$ $\Omega^{20}$. Mohiuddin and Hoa obtained a resistance of about $10^{3} \Omega$ for polyether ether ketone/CNT composite fiber ${ }^{21}$. In electrospun PA66/MWCNT fibers, the conductive pathways are formed through MWCNT network, and by the excellent conductivity of composite it comes to the conclusion of good dispersion of MWCNT in composite. The lower electrical resistance results in higher MWCNT content in nanocomposite which can be the result of enhancing the possibility of MWCNT contacts in the same area.

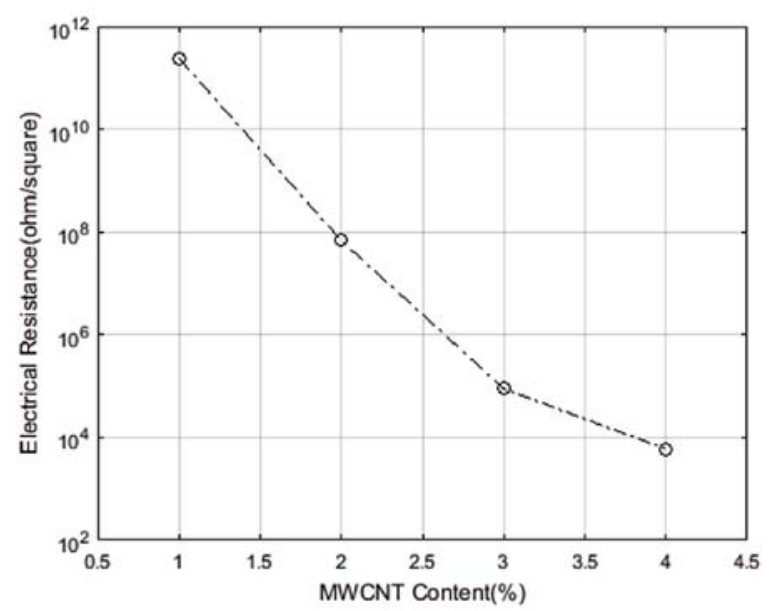

Figure 4. Conductivity of various MWCNT loadings for electrospun fibers

\section{UV blocking}

Many health problems of ultraviolet radiation have been proven such as cancers and erythema. Hence, UVblocking fabrics have attracted much attention in the last decade. These fabrics are produced via different methods such as sol-gel, dry pad and finishing techniques ${ }^{22}$. UV-blocking property of fabrics is illustrated by UPF (ultraviolet protection factor). This factor is measured via Eq. 2. In this equation, $E \lambda$ is the relative erythemal spectral effectiveness, $T \lambda$ is the spectral transmittance of the specimen, $\mathrm{S} \lambda$ is the solar UV spectral irradiance and $\mathrm{d} \lambda$ is the wavelength increment. The UV transmittance diagram of raw sample and treated samples are presented in Figure 5 (in the range of 200-400 nm). As it is shown, the transmittance spectrum of treated samples is lower than that of the raw sample. It means that UV protection of PA66/MWCNTs is higher. This is due to UV absorption ability of carbon nanotubes. The UPF of the raw sample is 6 , which has no protection against transmittance of UV irradiation. However, the measured UPF of the treated samples is $68,105,143,189$ for samples A, B, C and D, respectively. As a consequence, the samples with MWCNT have better UV protection compared to the raw sample due to UV absorption ability of MWCNT.

$U P F=\frac{\int_{200}^{400} E \lambda \times S \lambda \times d \lambda}{\int_{200}^{400} E \lambda \times S \lambda \times T \lambda \times d \lambda}$

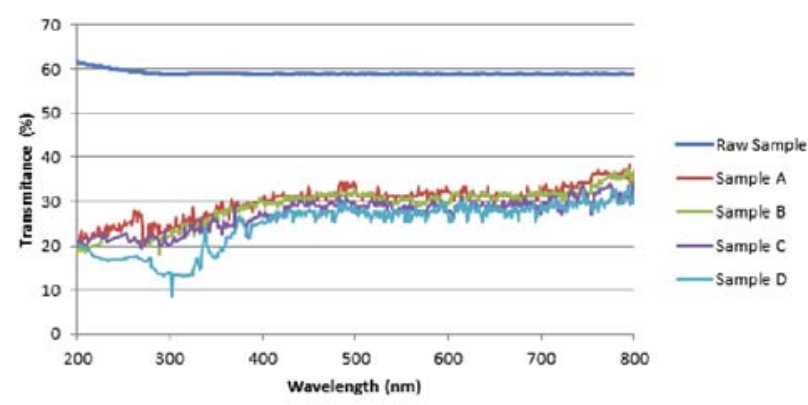

Figure 5. UV transmittance diagram of samples

\section{Antibacterial properties}

Using reactive oxygen species can cause to oxidation of proteins, nucleic acids lipids and DNA which can leads to bio cells destruction ${ }^{25}$. Musico and Liu were reported that carbon compounds produce reactive oxygen species ${ }^{26-27}$. Carbon compounds including graphene, mesopores carbon, graphene oxide and carbon nanotubes are well known because of their special properties like antibacterial activity ${ }^{27-30}$. Antibacterial and antimicrobial properties of carbon materials such as fullerene and carbon nanotube have been reported by Krishnamoorthy and Zhang ${ }^{31-32}$. The antimicrobial efficiency of the treated fabrics was tested against both Gram-positive (S. aureus) and Gram-negative (E. coli) bacteria. The $S$. aureus bacterium is a pathogenic micro-organism causing many diseases such as toxic shock, purulence, abscess, fibrin coagulation, and endocarditic. Moreover, E. coli bacterium which causes urinary tract and wound infections is a popular test organism ${ }^{23}$.

The result of the antibacterial test is reported in Figure 6. There is no meaningful reduction of bacteria on the raw sample while the samples treated with MWCNT had the proper antibacterial activity against both $S$. aureus and E. coli bacteria. The antibacterial activity of the samples treated with MWCNT was about $96.8 \%$ and $98 \%$ for $S$. aureus and E. coli bacteria, respectively. In other words, combining MWCNT with PA66 has improved the antibacterial activity of web. Moreover, samples showed better efficiency against $E$. coli in comparison with S. aureus. This can be explained by the difference in the thicknesses of the cell walls; $S$. aureus has a thicker cell wall.

Table 2. Electrical resistivity of samples

\begin{tabular}{|c|c|c|c|c|c|}
\hline Sample & RAW & A & $\mathrm{B}$ & C & D \\
\hline MWCNT\% & $0 \%$ & $1 \%$ & $2 \%$ & $3 \%$ & $4 \%$ \\
\hline Electrical resistivity [ $\Omega /$ square] & $\infty$ & $24 \times 10^{10}$ & $68 \times 10^{6}$ & $89 \times 10^{3}$ & $5.9 \times 10^{3}$ \\
\hline
\end{tabular}




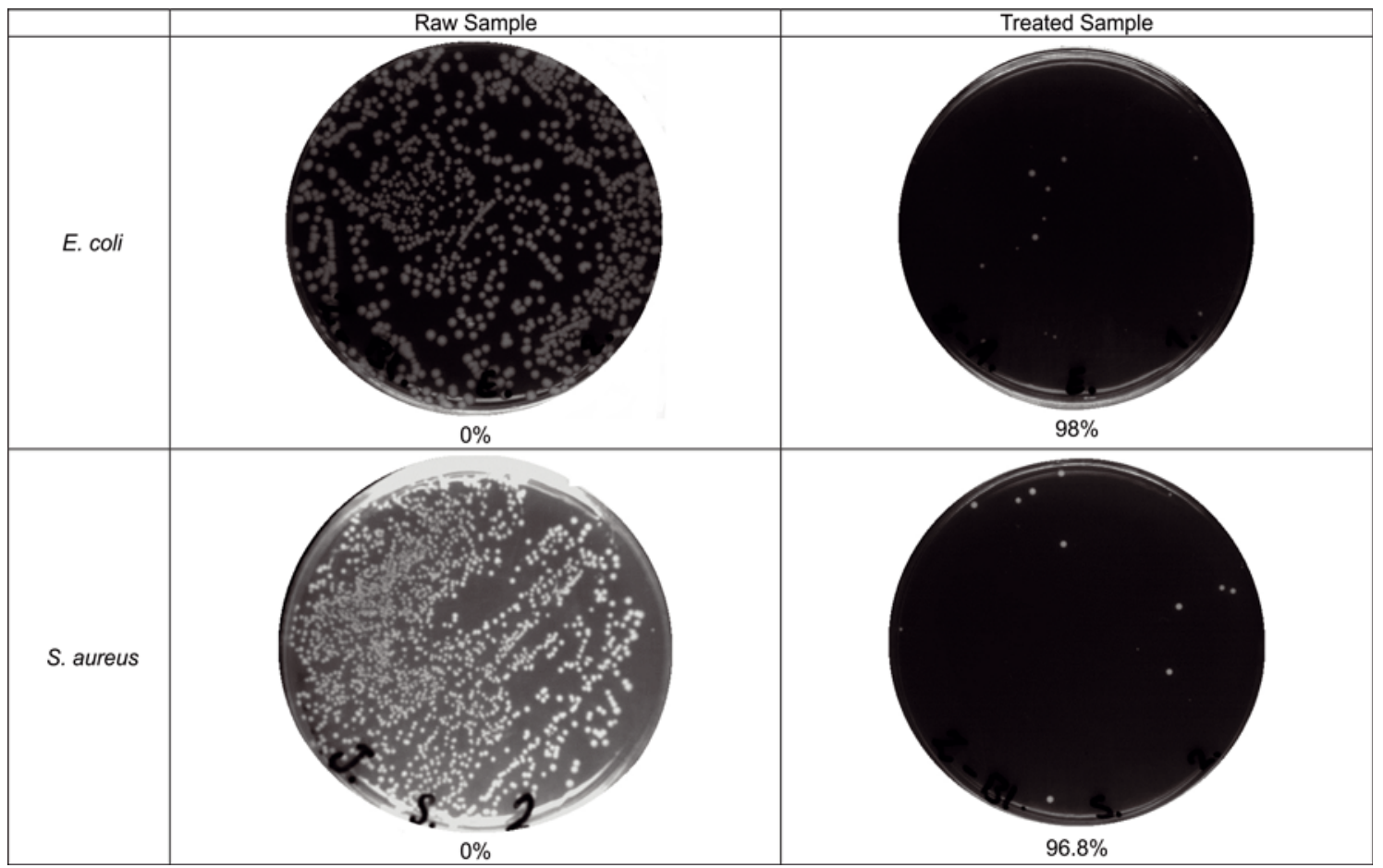

Figure 6. Antibacterial efficiency of raw and treated samples

\section{CONCLUSION}

In this study, MWCNT/PA66 nanocomposites were successfully fabricated by electrospinning method with multifunctional properties. Electrical conductivity, suitable antibacterial property and UV blocking activities were obtained. Through FTIR pattern, and FE-SEM images, the successful distribution of multi-walled carbon nanotube on the base of polyamide66 was verified. Moreover, the morphologies of electrospun nanofibers were illustrated without any beads. Fabrication of PA66 with MWCNT improved some properties of this nanocomposite such as antibacterial activity and UV blocking, which can help with prevention of various diseases.

\section{LITERATURE CITED}

1. Cai, J.Y. \& Min, J. et al. (2014). Enhanced mechanical performance of CNT/Polymer composite yarns by $\gamma$-irradiation. Fibers Polym. 15(2), 322-325. DOI: 10.1007/s12221-014-0322-9.

2. Chien, A-T. \& Cho, S. et al. (2014). Electrical conductivity and Joule heating of polyacrylonitrile/carbon nanotube composite fibers. Polymer 55(26), 6896-6905. DOI: http://dx.doi. org/10.1016/j.polymer.2014.10.064.

3. Dallmeyer, I. \& Lin, L.T. et al. (2014). Preparation and Characterization of Interconnected, Kraft Lignin-Based Carbon Fibrous Materials by Electrospinning. Macromol. Mater. Engine. 299(5), 540-551. DOI: 10.1002/mame.201300148.

4. Hunley, M.T. \& Pötschke, P. et al. (2009). Melt Dispersion and Electrospinning of Non-Functionalized Multiwalled Carbon Nanotubes in Thermoplastic Polyurethane. Macromol. Rapid Commun. 30(24), 2102-2106. DOI: 10.1002/marc.200900393.

5. Inagaki, M. \& Yang, Y. et al. (2012). Carbon Nanofibers Prepared via Electrospinning. Adv. Mater. 24(19), 2547-2566. DOI: 10.1002/adma.201104940.

6. Karimi, L. \& Zohoori, S. et al. (2014). Multi-wall carbon nanotubes and nano titanium dioxide coated on cotton fabric for superior self-cleaning and UV blocking. New Carbon Mater. 29(5), 380-385. DOI: http://dx.doi.org/10.1016/S18725805(14)60144-X

7. Ketpang, K. \& Park, J.S. (2010). Electrospinning PVDF/PPy/MWCNTs conducting composites. Synth. Metals
160(15-16), 1603-1608. DOI: http://dx.doi.org/10.1016/j.synthmet.2010.05.022.

8. Kim, K. \& Shim, H. et al. (2016). Fiber formation model for electrospinning. II. Stable jet voltage. Fibers Polym. 17(10), 1634-1640. DOI: 10.1007/s12221-016-6035-5.

9. Kimmer, D. \& Slobodian, P. et al. (2009). Polyurethane/ multiwalled carbon nanotube nanowebs prepared by an electrospinning process. J. Appl. Polym. Sci. 111(6), 2711-2714. DOI: $10.1002 /$ app.29238.

10. Lee, C.J. \& Salehiyan, R. et al. (2016). Influence of carbon nanotubes localization and transfer on electrical conductivity in PA66/(PS/PPE)/CNTs nanocomposites. Polymer 84, 198-208. DOI: http://dx.doi.org/10.1016/j.polymer.2015.12.055.

11. Liu, C.K. \& Lai, K. et al. (2009). Preparation of carbon nanofibres through electrospinning and thermal treatment. Polym. Int. 58(12), 1341-1349. DOI: 10.1002/pi.2669.

12. Martin, J.R. \& Borchardt, L. et al. (2013). Titanium Carbide and Carbide-Derived Carbon Composite Nanofibers by Electrospinning of Ti-Resin Precursor. Chem. Ingen.Technik 85(11), 1742-1748. DOI: 10.1002/cite.201300057.

13. Mirjalili, M. \& Zohoori, S. (2016). Review for application of electrospinning and electrospun nanofibers technology in textile industry. J. Nanostruct. Chem. 6(3), 207-213. DOI: 10.1007/s40097-016-0189-y.

14. Mohiuddin, M. \& Van Hoa, S. (2011). Electrical resistance of CNT-PEEK composites under compression at different temperatures. Nanoscale Res. Lett. 6(1), 1-5. DOI: 10.1186/1556-276x-6-419.

15. Montazer, M. \& Behzadnia, A. et al. (2011). Photo induced silver on nano titanium dioxide as an enhanced antimicrobial agent for wool. J. Photoch. Photob. B: Biology 103(3), 207-214. DOI: http://dx.doi.org/10.1016/j.jphotobiol.2011.03.009.

16. Oh, G.Y. \& Ju, Y.W. et al. (2008). Adsorption of toluene on carbon nanofibers prepared by electrospinning. Sci. Tot. Environ. 393(2-3), 341-347. DOI: http://dx.doi.org/10.1016/j. scitotenv.2008.01.005.

17. Pan, C., Ge, L.Q. et al. (2007). Fabrication of multi-walled carbon nanotube reinforced polyelectrolyte hollow nanofibers by electrospinning. Comp. Sci. Technol. 67(15-16), 3271-3277. DOI: http://dx.doi.org/10.1016/j.compscitech.2007.03.036.

18. Tian, M. \& Hu, X. et al. (2016). Ultraviolet protection cotton fabric achieved via layer-by-layer self-assembly of gra- 
phene oxide and chitosan. Appl. Surf. Sci. 377, 141-148. DOI: http://dx.doi.org/10.1016/j.apsusc.2016.03.183.

19. Wu, X.F. \& Rahman, A. et al. (2013). Electrospinning core-shell nanofibers for interfacial toughening and self-healing of carbon-fiber/epoxy composites. J. Appl. Polym. Sci. 129(3), 1383-1393. DOI: 10.1002/app.38838.

20. Wu, Z. \& Meng, L. et al. (2014). Chemically grafting carbon nanotubes onto carbon fibers by poly(acryloyl chloride) for enhancing interfacial strength in carbon fiber/unsaturated polyester composites. Fib. Polym. 15(3), 659-663. DOI: 10.1007/ s12221-014-0659-0.

21. Yang, T. \& Wu, D. et al. (2011). Electrospinning of polylactide and its composites with carbon nanotubes. Polym. Compos. 32(8), 1280-1288. DOI: 10.1002/pc.21149.

22. Yousef, A. \& Brooks, R.M. et al. (2015). Cu0-decorated, carbon-doped rutile $\mathrm{TiO}_{2}$ nanofibers via one step electrospinning: Effective photocatalyst for azo dyes degradation under solar light. Chem. Engine. Proces.: Process Intensif. 95, 202-207. DOI: http://dx.doi.org/10.1016/j.cep.2015.06.015.

23. Zohoori, S. \& Karimi, L. et al. (2014). A novel durable photoactive nylon fabric using electrospun nanofibers containing nanophotocatalysts. J. Ind. Engine. Chem. 20(5), 2934-2938. DOI: http://dx.doi.org/10.1016/j.jiec.2013.10.062.

24. Arboleda-Clemente, L. \& Ares-Pernas, A. et al. (2016). Influence of polyamide ratio on the CNT dispersion in polyamide $66 / 6$ blends by dilution of PA66 or PA6-MWCNT masterbatches. Synth. Metals 221, 134-141. DOI: https://doi. org/10.1016/j.synthmet.2016.07.030.

25. Hanaa, M. Hegab, A., El Mekawy, Zou, L., Mulcahy, D., Saint, C.P. \& Ginic-Markovic, M. (2016). The Controversial Antibacterial Activity of Graphene-Based Materials. Carbon. 105, 362-76. DOI: https://doi.org/10.1016/j.carbon.2016.04.046.

26. Shaobin, L., Tingying, H. Zeng, Mario Hofmann, Ehdi Burcombe, Jun Wei, Rongrong Jiang, Jing Kong \& Yuan Chen. (2011). Antibacterial Activity of Graphite, Graphite Oxide, Graphene Oxide, and Reduced Graphene Oxide: Membrane and Oxidative Stress. ACS Nano 5, 6971-80. DOI: 10.1021/ nn202451x.

27. Yvonne Ligaya F. Musico, Catherine M. Santos, Maria Lourdes P. Dalida, Debora F. Rodrigues. (2014). Surface Modification of Membrane Filters Using Graphene and Graphene Oxide-Based Nanomaterials for Bacterial Inactivation and Removal, ACS Sust. Chem. \& Engine. 2, 1559-65. DOI: $10.1021 / \mathrm{sc} 500044 \mathrm{p}$.

28. Virender K. Sharma, Thomas J. McDonald, Hyunook Kim, Vijayendra K. Garg. (2015). Magnetic Graphene-Carbon Nanotube Iron Nanocomposites as Adsorbents and Antibacterial Agents for Water Purification. Adv. Coll. Inter. Sci. 225, 229-40. DOI: https://doi.org/10.1016/j.cis.2015.10.006.

29. Tengfei Tian, Xiaoze Shi, Liang Cheng, Yinchan Luo, Ziliang Dong, Hua Gong, Ligeng Xu, Zengtao Zhong, Rui Peng, and Zhuang Liu. (2014). Graphene-Based Nanocomposite as an Effective, Multifunctional, and Recyclable Antibacterial Agent. ACS Appl. Mater. \& Inter. 6, 8542-48. DOI: 10.1021/ am5022914.

30. Oya, A., Yoshida, S., Alcaniz-Monge, J. \& Linares-Solano, A. (1996). Preparation and Properties of an Antibacterial Activated Carbon Fiber Containing Mesopores. Carbon 34, 53-57. DOI: https://doi.org/10.1016/0008-6223(95)00134-4.

31. Karthikeyan Krishnamoorthy, Murugan Veerapandian, Ling-He Zhang, Kyusik Yun, and Sang Jae Kim. (2012). Antibacterial Efficiency of Graphene Nanosheets against Pathogenic Bacteria Via Lipid Peroxidation. J. Phys. Chem. C. $116,17280-87$. DOI: 10.1021/jp3047054.

32. Yongbin Zhang, Syed F. Ali, Enkeleda Dervishi, Yang $\mathrm{Xu}$, Zhongrui Li, Daniel Casciano, and Alexandru S. Biris. (2010). Cytotoxicity Effects of Graphene and Single-Wall Carbon Nanotubes in Neural Phaeochromocytoma-Derived Pc12 Cells. ACS Nano. 4, 3181-3186. DOI: 10.1021/nn1007176. 